\title{
APUNTES SOBRE LA IMPLANTACIÓN DEL ESTANCO DEL TABACO EN EL VIRREINATO DEL PERÚ (1752- 1762)
}

\author{
NOTES ON THE ESTABLISHMENT OF THE STATE \\ TOBACCO MONOPOLY IN THE VICEROYALTY OF \\ PERU (1752-1762)
}

\author{
Juan luis Orrego Penagos \\ Universidad de Lima
}

\section{RESUMEN}

El presente artículo expone el panorama de la producción, consumo e impacto fiscal del tabaco en el Virreinato del Perú hacia mediados del siglo XVIII, cuando la Corte de Madrid, como parte del reordenamiento borbónico, implantó el estanco del tabaco. A continuación, se analizan las razones y las dificultades de su establecimiento, así como los efectos en las rentas de la Corona durante los primeros diez años de vigencia del nuevo privilegio o monopolio estatal. Las limitaciones y vicios de la administración virreinal son también el telón de fondo en esta etapa inicial del estanco del tabaco, que recorrió gran parte del gobierno del virrey conde de Superunda (1745-1761), y un fragmento del de Manuel de Amat y Junyent (1761-1776).

Palavras clave: Tabaco, Virreinato del Perú, reformas borbónicas, fiscalidad, siglo XVIII, conde de Superunda, Manuel de Amat.

\begin{abstract}
This paper presents the panorama of the production, consumption and fiscal impact of tobacco in the Viceroyalty of Peru around the mid eighteenth century, when the Court of Madrid, as part of the Bourbon reorganisation, established a state monopoly on the tobacco industry. The reasons and difficulties involved in its establishment are then analysed, in addition to the effects on the income of the Crown during the first years of operation of the new privilege or state monopoly. The limitations and vices of the viceregal administration are also the backdrop to this initial stage of the state's tobacco monopoly, which covered most of the government of the Viceroy Count of Superunda (1745-1761), and part of the government of Manuel de Amat y Junyent (1761-1776).
\end{abstract}

Keywords: tobacco, Viceroyalty of Peru, Borbon reforms, taxation, 18th century, Count of Superunda, Manuel de Amat. 


\section{RESUM \\ APUNTS SOBRE LA IMPLANTACIÓ DE L'ESTANC DEL TABAC AL VIRREGNAT DEL PERÚ (1752-1762)}

Aquest artícle exposa el panorama de la producció, consum i impacte fiscal del tabac al Virregnat del Perú cap a mitjans del sigle XVIII, quan la Cort de Madrid, com a part del reordenament borbònic, va implantar l'estanc del tabac. A continuació, s'analitzen les raons i les dificultats del seu establiment, així com els efectes sobre les rendes de la Corona durant els primers deu anys de vigència del nou privilegi o monopoli estatal. Les limitacions i vicis de l'administració del virregnat són també el rerrafons en aquesta etapa inicial de l'estanc del tabac, que va recòrrer gran part del govern del virrei comte de Superunda (1745-1761), i un fragment del de Manuel de Amat i Junyent (1761-1776).

Paraules clau: Tabac, Virregnat del Perú, reformes borbòniques, fiscalitat, segle XVIII, comte de Superunda, Manuel de Amat 
"Con el designio de proporcionar... á sus vasallos, ... establecieron nuestros amables monarcas el Estanco de Tabacos. De suerte que aunque es un derecho inherente a la soberanía imponer tributos sobre las cosas de puro luxo para proveer a los gastos de la Corona; el fin supremo que originó la Real Administración de Tabacos fue la salud del pueblo" (Hipólito Unanue. Mercurio Peruano, 15 de enero de 1792).

La idea de implantar un estanco del tabaco no era nueva en el Virreinato del Perú. Ya en 1674, el virrey de Lima, el conde de Castellar, planteó que se le concediera el derecho de vender el tabaco a un particular. Además, ya existían, desde el siglo XVII, otros rubros estancados como el papel sellado, la coca, el azogue, el solimán y la pimienta. Pero aquel proyecto no prosperó, como lo anota Guillermo Céspedes del Castillo (1954), pionero del estudio de la renta del tabaco en el Perú virreinal. ${ }^{1}$

1 Luego del trabajo precursor del gran americanista Céspedes del Castillo, vinieron algunos estudios, muy parciales, sobre el estanco del tabaco, y siempre dentro del impacto de las reformas borbónicas en el Virreinato del Perú, por parte de algunos historiadores peruanos, los interesados en la vida económica del siglo XVIII como Javier Tord, Carlos Lazo, Pablo Macera - Guillermo Lohmann, y de un investigador norteamericano, Herbert S. Klein. En España, a Céspedes del Castillo lo siguió Alfredo Moreno Cebrián (por sus estudios sobre el virrey conde de Superunda). En los últimos años, contamos con los aportes de Magdalena Chocano, Francisco Quiróz y Ramiro Flores (todos ellos citados en este trabajo) y, especialmente, la sólida investigación monográfica del historiador sanmarquino Carlos Morales Cerón, que también hemos consignado en este ensayo. Todos estos trabajos, sin embargo, se concentran en la perspectiva económica y fiscal del tabaco y su estanco; falta aún la proyección social y cultural del consumo del tabaco no sólo en la etapa final del Virreinato peruano sino también en la temprana República. 
Un segundo momento vino con la llegada al trono del rey Fernando $\mathrm{VI}$ (1746-1759), en que los asuntos del Nuevo Mundo cobraron mayor atención en la metrópoli, especialmente por los eternos apremios de la Real Hacienda. Fue en ese ambiente de cirugías fiscales que el contador Pedro Antonio del Castillo y San Juan propuso estancar no sólo el tabaco sino también el papel blanco para la elaboración de los cigarrillos. Céspedes del Castillo (1992) calculó que, en ese momento, el consumo de tabaco en el Perú era de cien mil libras, cuya venta se acercaba a los dos millones de pesos.

Sin embargo, como ya se sabe, el proyecto que tuvo mayor repercusión para el Virreinato peruano, en la Corte de Madrid, fue el que presentó el contador mayor Tomás Chavaque y Herreros, el 4 de agosto de 1746, para estancar los tabacos de polvo y rama. El documento, con sus instrucciones, fue aprobado el 27 de octubre de aquel año por el Consejo de Indias, y remitido al entonces Virrey del Perú, José Antonio Manso de Velasco, futuro conde de Superunda. La idea era que el nuevo estanco de Lima imitara la gestión de la oficina de su similar en España.

No obstante, una serie de contratiempos, como el gran terremoto que destruyó la Ciudad de los Reyes en 1746, impidió que el monopolio estatal se implantara. Recién fue posible en 1752. Luego, en 1759 se estableció el real estanco, con el objetivo de recaudar las rentas generadas por el comercio del tabaco. En el periodo que va de 1752 a 1779, el Estado borbónico cumplió con su atribución de controlar de manera exclusiva la producción y distribución de la hoja del tabaco. En esa perspectiva, nuestro trabajo pretende abarcar los diez primeros años del funcionamiento del estanco del tabaco.

\section{La producción, el CONSUMO Y la Venta del tabaco en el Perú}

El panorama del tabaco en la América hispana tenía en el Virreinato del Perú un matiz especial, debido a la producción y el consumo extendidos de la tradicional hoja de coca al interior de la población indígena, que representaba casi un $70 \%$ de la población. Por ello, en sus diversas formas, el tabaco era demandado, básicamente, en las ciudades y haciendas de la costa, donde había otro tejido social (blancos, negros y mestizos), con distintos hábitos de consumo, más vinculados a los dictados por el mundo trasatlántico.

Las ciudades de Lima y Trujillo monopolizaban las principales fábricas de cigarrillos y, por el Callao, ingresaba el tabaco proveniente de Nueva España y el Caribe. Es evidente, por último, que ya en el siglo XVIII se había consolidado el uso moderno del tabaco como simple diversión, y 
para estimular el sistema nervioso o para "calmar" las tensiones en una sociedad urbana cada vez más proclive al conflicto, atizado por la creciente mezcla racial. También sirvió como vehículo (como ocurriría luego con el café) para crear nuevos espacios de identidad y socialización. Los establecimientos donde se vendía tabaco en Lima se encontraban en las zonas aledañas a la Plaza Mayor y en los alrededores del Corral de Comedias, en la calle Coliseo (actual segunda cuadra del jirón Huancavelica). Mucha gente de la plebe limeña, como parte de sus diversas estrategias en subsistir, adquiría el tabaco en estas tiendas y elaboraba, en sus propias viviendas, cigarros, limpiones y rapé que luego vendía al menudeo a través del comercio callejero o en las pulperías de Lima o de otros pueblos del interior (QUIROZ, 2010). ${ }^{2}$

Antes que en forma de cigarrillos, el tabaco en polvo o rapé (llamado "polvo de Lima", a pesar de que se producía en La Habana) era el más consumido por la elite blanca en sus salones aristocráticos. La alta burocracia, en cambio, durante su jornada laboral, prefería el tabaco hecho cigarro. Otros testimonios, un tanto exagerados, apuntan que era un vicio "propio de la vejez", aunque también se indica que las mujeres tenían más tendencia al uso del tabaco en hoja (o las pequeñas motillas que utilizaban las damas para la limpieza de los dientes). Igualmente, en forma de hoja, pero de mucho menor calidad, era mayormente distribuido para castas, negros y mulatos, quienes lo asociaban al alivio y entretenimiento en el trabajo, tanto en los ambientes urbanos (panaderías y talleres de todo tipo) como en las haciendas.

Ahora bien, si el consumo el tabaco tuvo relativa importancia en el Perú, estuvo muy lejos de la magnitud que alcanzó en el Caribe o en México. Sólo si hacemos la comparación en términos de virreinatos, en Nueva España

2 Esta problemática social fue advertida por varios intelectuales de la época, especialmente por Hipólito Unanue, acaso el personaje más destacado de la elite ilustrada limeña: "Todos saben que el Perú es uno de los países del mundo en que hay menos recursos para que subsista la gente pobre. Viniendo hecho de la Europa del zapato a la gorra queda muy corto espacio a los Peruleros en el exerci [ci] o de las artes mecánicas. El tabaco alimentaba entonces a un número crecido de familias no sólo en Lima, sino en todo el reyno. El indigente padre de familias ocurría a la tercena, y a costa de un corto precio conseguía un buen mazo. Lo reducía a cigarros ayudado de sus hijos, y en su venta y corta ganancia encontraba el medio seguro de subsistir" (UNANUE, 1964-1966 [1792]: 47). Redactor del Mercurio Peruano, la revista científica más influyente del siglo XVIII peruano, a Unanue y a su artículo citado, los vamos a utilizar reiteradamente en este ensayo. 
el tamaño del mercado o la cantidad de población era muy superior: 6 millones de mexicanos frente a 1,5 millones de peruanos hacia la década de 1790. Además, como hemos apuntado, en el Perú los amantes del humo eran una minoría urbana y costeña, frente a una masa indígena que prefería otros estimulantes, como la mencionada hoja de coca, y también la chicha de maíz, una bebida ancestral. Ambos consumos, además, estaban asociados a contextos rituales y festivos.

A pesar de este consumo, aparentemente reducido del tabaco, la producción local no alcanzaba para cubrir la demanda o los deseos de los fumadores limeños. Según algunos cálculos consignados, llegamos a la sorprendente cifra de que Lima alcanzó a adquirir el $29 \%$ del total de las exportaciones cubanas de tabaco, esto es el $57 \%$ del total o polvo de tabaco proveniente de La Habana (CHOCANO, 2005).

Respecto a la producción interna, el tabaco se cultivaba en la costa norte del Virreinato, dominada por el extenso corregimiento de Trujillo, de clima templado, con ausencia de lluvias, principalmente en la provincia de Saña, y otras como Ferreñafe, Chiclayo, Guadalupe y San Pedro: este tabaco era llamado "yunga" o "criollo". Otra área de cultivo, también bajo la jurisdicción del corregimiento de Trujillo, se ubicaba más al Oriente, en zona de Ceja de Selva, de bosque semi-tropical, en Chachapoyas y Moyobamba (y otras localidades menores como Guayabamba, Sipasbamba, Sesuya y Chillos). Este tabaco era conocido como el "yunga".

Sin embargo, en la zona oriental, la producción más importante venía de Jaén de Bracamoros que, aunque pertenecía a la parte más meridional de la jurisdicción de la Audiencia de Quito, para todos sus asuntos jurídicos y comerciales estaba bajo el control de las autoridades de Lima. Rodeada por Piura, Lambayeque, Chota y Chachapoyas, debido también a su clima templado, Jaén era ideal para el cultivo del tabaco, y formaba parte de un dinámico circuito comercial que tenía a Piura como su cabeza de región, seguida por Guayaquil.

Respecto a su producción tabacalera antes del establecimiento del estanco, "Desde 1725 a 1743, según los libros reales de la Real Hacienda de la provincia de Jaén de Bracamoros, se embarcaron para Lima la suma de 17,525 fardos de tabaco, los que ingresaron por mar y tierra. En total $1,172,500$ mazos de tabaco, que es el promedio establecido según los contadores del tribunal de cuentas, quienes calculaban cada fardo a la suma de cien mazos cada una. En total a cada año le corresponde la suma de 94,729 mazos vendidos en la capital" (MORALES, 2013: 151). Estos mazos eran puntualmente trasladados por los arrieros y sus mulas desde Jaén hasta la provincia de Saña, ubicada a medio camino entre el mar y 
la cordillera de los Andes, a unos 50 kilómetros de Chiclayo, y allí enviado a las ciudades de Piura, Trujillo y Lima, y haciendas de la costa. El flete de Saña hasta Lima, por ejemplo, se pagaba en 12 pesos la carga, y cada una equivalía a cuatro fardos. Cabe destacar que este tabaco, también llamado "bracamoros", no sólo abastecía el mercado interno, sino también llegó a Chile y al Río de la Plata. ${ }^{3}$

El siguiente cuadro nos demuestra que, antes del establecimiento formal del estanco del Tabaco, en los campos de Saña y Jaén se cultivaba más del $90 \%$ del tabaco peruano. Este comercio interno de tabaco estaba sometido al pago de la alcabala. El tabaco fino se traía de La Habana, cuyo principal mercado de consumidores estaba, como antes apuntábamos, en la Lima cortesana.

La crecida demanda no sólo se debió a la calidad o lo agradable del tabaco, sino también al precio. Los tabacos en rama eran muy baratos. En cambio, el tabaco en polvo era un poco más caro, ya que era importado. Se trataba de un artículo de lujo, solicitado intensamente por los grupos privilegiados de Lima. Ahora, el mayor o menor aumento de consumo dependió, obviamente, del estado demográfico de la población. En el transcurso del siglo XVIII, luego de la gran epidemia de 1720, se produjo un gradual crecimiento de la población en todas las provincias en el interior del Virreinato, así como el intenso mestizaje social que le dieron un nuevo rostro a las ciudades de la costa, especialmente a la capital del Virreinato, con nuevas castas o mezclas raciales: en 1700, Lima contaba con 35.000 habitantes y, en 1790, llegó a los 52.000; Trujillo alcanzó los 9.200 en 1760; y Piura los 12.300 en 1790. Pero, aun así, eran núcleos urbanos de segundo orden, en comparación a los de Nueva España.

\section{LAS JUSTIFICACIONES PARA EL ESTANCO DEL TABACO}

Antes de establecerse el estanco o monopolio estatal, el comercio del tabaco, como el de otros productos, estaba afecto al cobro de alcabala y almojarifazgo. El problema es que casi el $80 \%$ del volumen que se comerciaba no pagaba impuestos. Había que actuar, la evasión era un escándalo no sólo fiscal sino de eficiencia administrativa y política. ${ }^{4}$

3 También había pequeñas siembras de tabaco en Guayaquil, Cuzco, La Paz, Cochabamba y Paraguay.

4 Cabe añadir que también hubo el intento de estancar el aguardiente de caña y de uva, pero no prosperó. En el caso de dichos productos, se decidió por gravarlos con impuestos más altos. 
Son ya conocidos los móviles comerciales y fiscales para establecer un estanco (una operación fácil e inmediata de obtener rentas), y con el del tabaco se añadió el relativo a la "salud pública". En este sentido, el primer objetivo fue extirpar el comercio ilícito y el contrabando, ambos ya incontrolables, y que ridiculizaban la autoridad virreinal. El contador Tomás Chavaque, recogiendo las denuncias de los comerciantes, sostenía que el estanco era necesario para detener el comercio paralelo e informal que venía desde México y Panamá hacia el Perú, y que era desembarcado en las caletas del "norte chico" de Lima, como Barranca y Chancay. También se tenían noticias de descargas clandestinas en las cercanías del puerto de Paita, en Piura, al norte del Virreinato.

Estas anomalías, como tantas otras en la vida económica del Virreinato peruano, alteraban el normal desarrollo de los pagos de impuestos y afectaban a la Real Hacienda. No podía tolerarse un circuito de comercio y de transacciones al margen de la ley. Se sabe también que los mismos comerciantes dedicados al tráfico del tabaco eludían el pago de la alcabala ocultando la verdadera cantidad de fardos con tabaco. Otra estrategia era agregar una mayor cantidad de mazos de tabaco en cada fardo que terminaban casi siempre por sobrecargar los envases con más tabaco del permitido. Esta "técnica" evitaba los registros y el conteo, además de tener la colaboración de funcionarios venales que hacían de la vista gorda en el momento de realizar sus inventarios. También había falta de control para cobrar los almojarifazgos de entrada o salida del tabaco por las aduanas, lo que hacía florecer el tráfico informal.

Todo esto creaba un peligroso agujero en la Real Hacienda. Además, el propio Chavaque advertía sobre el problema del déficit de la Caja Fiscal, que llegaba a 200 mil pesos anuales en el caso del Perú. Esto impedía atender las urgencias que debían enfrentar las autoridades del Estado en otras áreas de su gestión (MORALES, 2012 y 2015).

En suma, la falta de ingresos y el descontrol sobre el contrabando, denunciado por Chavaque y por el mismo Virrey conde de Superunda, fueron razones categóricas para el estancamiento del tabaco. Además, la justificación estaba sustentada en el principio de dominio económico que tenía la autoridad real sobre el Virreinato del Perú. En otras palabras, como todo ramo que producía recaudación tenía como primer nombre el título real por pertenecer al Rey en beneficio de sí y de los súbditos. Por lo tanto, el establecimiento del estanco no perjudicaría los intereses de los vasallos del rey del Virreinato peruano, ya que la implementación de esta empresa dependía de la voluntad real para satisfacer las urgencias del Estado, según el Contador general. 
En sentido más amplio, ya la teoría política y el pensamiento jurídico del siglo XVIII avalaban el convencimiento de que el Estado se podía arrogar el derecho, inherente a su soberanía, de gravar con tributos especiales los artículos de lujo para cubrir los gastos que demandaban las urgencias públicas, tan cambiantes sobre todo en un contexto imperial, en el que la metrópoli debía enfrentar, por ejemplo, la emergencia de conflictos internacionales, donde el escenario bélico podía desatarse en Europa o en las costas de las posesiones ultramarinas. Las innumerables crisis del siglo XVIII mantuvieron en estado de alerta permanente a los funcionarios borbónicos, que forzaron a discreción, no sin protestas o estallidos sociales, su intervencionismo, especialmente el fiscal. Centralizar, controlar y recaudar fueron, en gran medida, la esencia de las reformas borbónicas.

Respecto a la tercera "razón", o el supuesto interés que tenía el Rey para proteger la salud pública, se apeló a la vieja creencia de que el tabaco era una hierba medicinal, recomendada para una serie de dolencias, especialmente las asmáticas y bronquiales. Algunos médicos del siglo XVIII le atribuyeron al tabaco ciertas virtudes para aliviar, incluso curar, algunas enfermedades. Un erudito de la época, el polígrafo José Eusebio Llano Zapata (Lima, 1721-Cádiz, 1780), en sus Memorias histórico, físicas, crítico apologéticas de la América Meridional defendía que el tabaco era propicio para combatir, por ejemplo, el dolor de cabeza: "colocadas sus hojas sobre la cabeza curaba los dolores de ella y todas las fluxiones del cuerpo que provienen del frío". Asimismo, el ilustrado limeño vinculabo al tabaco la propiedad de limpiar los pulmones y el sistema respiratorio. Explicaba que, cuando los pulmones estaban llenos de viscosidades, se podía preparar una especie de infusión ("decocción") de hoja de tabaco, con azúcar o miel. ${ }^{5}$

Claro que el pensamiento ilustrado también advertía sobre los evidentes efectos nocivos que producía el tabaco en el organismo y la salud. Por ello, funcionarios y hombres de ciencia justificaron el control del Estado en su distribución y venta para que la población pudiera consumir un tabaco de mejor calidad. Hipólito Unanue (Arica, 1755-Cañete, 1833), acaso el científico peruano más destacado de la época, insistió que el principal argumento de la Corona fue proteger la salud del pueblo. En el Mercurio Peruano, Unanue escribió: "Con el designio de proporcionar... a sus vasallos, ... establecieron nuestros amables monarcas el estanco de Tabacos. 
De suerte que aunque es un derecho inherente de la soberanía imponer tributos sobre las cosas de puro luxo para proveer los gastos de la corona; el fin supremo que originó la Real Administración de Tabacos fue la salud del pueblo". Como vemos, al insistir que con el estancamiento del tabaco se procedía humanitariamente hacia la población, Unanue añadió también el planteamiento regalista. ${ }^{6}$

El que debió establecer el estanco fue el Virrey conde de Superunda. En un primer momento, el monopolio debía abastecer los mercados de Lima y Santiago de Chile; luego, extenderse a las provincias del interior, como Arequipa, Cuzco y Huamanga, y, más adelante, debía ampliarse a Potosí y La Plata.

\section{El PRIMER ESCOLlO DEL ESTANCO DEL tABACO: El TERREMOTO DE LIMA}

No sólo el establecimiento del estanco del tabaco, sino otros proyectos vinculados a la política virreinal se vieron seriamente interrumpidos y postergados por el cataclismo que sufrió la Ciudad de los Reyes el viernes 28 de octubre de 1746 a las diez y media de la noche, aproximadamente. Aunque en esa época no existían registros ni mediciones científicas de los seismos, se calcula que, por su nivel de destrucción, el movimiento telúrico pudo alcanzar una magnitud de 8,4 en la escala de Ritcher, y duró entre 3 y 6 minutos, lo que explica también el feroz maremoto que, prácticamente, sepultó el puerto del Callao, ubicado a una distancia de diez kilómetros de la capital del Virreinato (CARCELÉN, MORÁN y AMADOR, 2020).

En Lima, que aún contaba con sus murallas construidas en la década de 1680 por el Virrey duque de la Palata, sólo quedaron en pie 25 inmuebles

6 El artículo de Unanue es acaso el mejor ensayo sobre el tabaco que se escribió en el Perú del siglo XVIII, pues va más allá de lo puramente económico o fiscal, y rastrea la complicada historia del tabaco desde los primeros años del Virreinato, y trasciende al Perú. La visión totalizadora de Unanue no es sólo la del funcionario, la del economista o del científico, tres ámbitos en los que el autor se manejó con amplia soltura, sino la del humanista, animador de la vida cultural de la época. Como muestra, citamos el antecedente más remoto, según Unanue, de establecer un estanco en la América meridional, que sitúa a mediados del siglo XVII, cuando se solicitó el privilegio del estanco a cambio de un servicio pecuniario: "esta proposición fue mirada con desprecio ya por las consecuencias fatales que debía inducir un monopolio de esta naturaleza, ya por las condiciones gravosas y perjudiciales a la causa pública, que incluía la protesta, y que hizo manifiestas al referido señor Virrey el Tribunal del Consulado" (UNANUE, 1964-1966 [1797]: 36). Cabe destacar, por último, que Unanue consideraba al tabaco como un "excelente preservativo de pestes". 
de los 3.500 que existían. Todo quedó en escombros, y los edificios más importantes se vieron seriamente afectados. Aquella urbe barroca, construida espléndidamente en el siglo XVII, y de la que muchos testimonios dieron fe, quedó sólo en el imaginario, para siempre. El barroco afrancesado, y, sobre todo, el neoclásico, se encargaron, poco a poco, de reconstruirla, hasta casi en los tiempos previos a las guerras por la Independencia. La tragedia humana fue de igual magnitud, no sólo por las 1.300 muertes, sino también por la gran cantidad de personas que quedaron desprotegidas, y otras que agudizaron su pobreza, por lo que muchos recursos, de los pocos que había, tuvieron que dedicarse a la obra social y la beneficencia. ${ }^{7}$

El estratégico puerto del Callao, que aún por esas fechas monopolizaba el comercio entre esta parte de la América meridional con la Península, quedó destruido por el cruel maremoto o tsunami (con olas de entre 10 y 24 metros) provocado por el cataclismo y que, salvando las distancias, se anticipó a la similar tragedia que sufrió Lisboa en noviembre de 1755. Sólo se salvaron 200 personas de las casi 5 mil que moraban en el puerto, y su infraestructura, incluyendo las murallas, prácticamente despareció. A las pérdidas, se sumó el irreparable daño comercial, pues toda la mercadería almacenada, tanto en tierra como en las naves, se perdió.

La crisis tuvo que enfrentarla el virrey Conde de Superunda, quien había llegado a Lima justo un año antes, en 1745, con el encargo de emprender una serie de reformas, como la impulsión del estanco del tabaco, pero todo lo tuvo que trastocar debido a la emergencia que vivían la ciudad y el puerto que dirigían los destinos de la jurisdicción virreinal más grande del Pacífico sur.

Sin embargo, a pesar de todos sus desvelos, el conde de Superunda ${ }^{8}$ no pudo contener lo que recién ahora la historiografía está advirtiendo con mayor nitidez: el peso de este desastre natural como factor del debilitamiento de Lima como centro burocrático y administrativo en la última etapa virreinal que antecedió a la Independencia. Tradicionalmente, los estudios históricos habían puesto todo el énfasis al efecto que trajeron las refor-

7 No sólo las instituciones eclesiásticas y de caridad se quedaron sin fondos para sus tareas, sino que el Virrey tuvo, como parte del proceso de reconstrucción, que decidirse por estrategias muy estrictas de control social como expulsar vecinos de las áreas dañadas dentro de la ciudad amurallada, así como castigos ejemplares a todo aquel que ocasionara saqueos y/o desmanes durante los trabajos de reconstrucción.

8 En reconocimiento a su encomiable labor para con la Ciudad de los Reyes, el Rey lo distinguió, en 1748, con un título nobiliario que reflejó todo aquel momento crítico, y que el mismo Virrey escogió: conde de Superunda, que quiere decir "sobre las olas". 
mas borbónicas, con sus ajustes fiscales, la liberación del comercio (con el fin del monopolio del Callao) y el reordenamiento administrativo-territorial (creación del Virreinato del Río de la Plata, en 1776, que incluyó la separación del Alto Perú, con la pérdida de la rentable Potosí), pero ya es un hecho que, sin el escenario de la destrucción de Lima y del Callao, la ciudad, el puerto y su elite hubieran podido afrontar de manera distinta, con otro respaldo financiero, con mayor nivel de presión o negociación, los ímpetus reformistas de la alta burocracia borbónica que operaba desde la corte de Madrid.

En síntesis, lo que queremos subrayar es que la aplicación del estanco del tabaco se dio en un periodo muy particular de reconstrucción de la capital del Virreinato, una empresa que significó la inversión de gran cantidad de dinero (que no salió de las Cajas Reales) y que, en realidad, no despertó la comprensión y/o ayuda de Madrid, ocupada entonces, entre otros desvelos, por una costosa guerra contra la alianza formada por la Gran Bretaña, el Sacro Imperio, las Provincias Unidas y Saboya-Cerdeña, en el contexto de la Guerra de Sucesión de Austria. ${ }^{9}$ El dinero público, entonces, antes de ser invertido en las ruinas, había que destinarlo a defenderse del ataque de los británicos, que habían extendido el conflicto europeo hasta el otro lado del Atlántico, bombardeando puertos estratégicos como Portobelo y Cartagena de Indias. Estamos, entonces, frente a una auténtica crisis general para Ciudad de los Reyes, con serias repercusiones económicas, urbanas y, desde luego, sanitarias y demográficas (Lima y el Callao perdieron el 8\% de su población). El virrey Manso de Velasco tuvo que ser muy diligente en enviar caudales a España, pues "pues en sus 16 años de gobierno mandó tres millones de pesos, de los cuales dos millones y medio fueron enviados entre 1748 y 1752 , el quinquenio clave en la reconstrucción de Lima" (PÉREZ-MALLAÍNA, 2005: 51).

Regresando a la problemática del tabaco, si la Real Hacienda no estaba en condiciones de asumir los gastos derivados de la reconstrucción de la ciudad, menos aún contaba con recursos para la instalación inmediata del estanco. La población también estaba arruinada, tanto así que el conde de Superunda, entre otras medidas para aliviar a los propietarios y deudores de crédito, ordenó rebajar a la mitad el pago de los censos que gravaban las propiedades inmobiliarias. Las autoridades, tanto en España como del Perú, no dudaron de la inconveniencia de aplicar el estanco. Por ello, el 19

9 En realidad, los gastos por la reconstrucción de Lima se prolongaron hasta la última década del siglo XVIII, por lo que estamos hablando de un caso estructural de inversión urbana. 
de marzo de 1751 se emitió la Real Orden, comunicada por el marqués de la Ensenada: "Lo que queda decir a su majestad en inteligencia, de que por los gastos causados por el terremoto ocurrido en 1746 no han podido ponerse en práctica el establecimiento de la renta en estos reynos pero espera SM se podrá a execución cuando lo considere conveniente" (cit. MORALES, 2012: 39).

Finalmente, otro impedimento en esta etapa fundacional del estanco fue la repentina muerte del contador Tomás Chavaque, a todas luces el más indicado para ser el máximo responsable de supervisar la nueva renta, por su vasta experiencia en el Tribunal Mayor de Cuentas. Era el perito en el comercio del tabaco, no había nadie como él con tal conocimiento sobre el tema, por toda la información que había recopilado.

\section{El establecimiento del estanco Y los PROBlemas de aplicación}

Después de tantas dilaciones, el momento llegó, por fin, el 26 de abril de 1752 cuando se difundió, a viva voz, entre la población limeña, el bando que estableció el estanco. El mandato cumplía la orden de Zenón de Somodevilla y Bengoechea, marqués de la Ensenada, en ese entonces Secretario del Despacho Universal de Indias. El Virrey, ya más calmado después de los efectos del terremoto, pudo organizar una junta especial para poner en práctica el estanco, compuesta por los oidores Pedro Bravo de Rivero y Pedro José Bravo de Castilla, el Maestre Escuela y Asesor General Francisco Herboso y el Fiscal en lo civil José Nieto.

En un primer momento, el dispositivo sólo afectó al tabaco en polvo, por lo que todo el producto existente que estuviese en manos de personas privadas debía remitirse a los nuevos funcionarios del estanco. Al año siguiente, se incluyó el tabaco en rama u hoja. Este proceso, más engorroso, venía acompañado por un fino trabajo de tasar las entregas de tabaco y establecer un cronograma de pagos por indemnización que, dependiendo de la zona y de los recursos disponibles, se efectuó en varias cuotas, en un plazo no mayor de dieciocho meses para su cancelación. Cabe agregar que el estanco tenía su propio aparato de administración, autónomo respecto del de la Real Hacienda.

Cuando culminó la primera etapa de tasación y reconocimiento de la deuda, vino el procedimiento regular. La oficina del estanco debía comprarles el tabaco a los cosecheros (para ello, negociaba contratos a largo plazo con ellos) o importarlo directamente de otras zonas de la América hispana. El tabaco local era acopiado en almacenes o factorías donde se enzurronaba para ser llevado por arrieros especialmente contratados a la Dirección General de Lima. En esta etapa, los estanqueros ya podían 
venderlo en forma de polvo, cigarros y cigarrillos en tiendas especiales, autorizadas, llamadas estanquillos. La norma establecía, además, que los ingresos producidos por el estanco no eran incluidos dentro de la contabilidad estatal sino enviados inmediatamente a España para que la Corona dispusiera de ellos a discreción. Hasta allí alcanzaba, en líneas generales, el funcionamiento normal o regular del estanco (CHOCANO, 2010).

Por lo tanto, la primera dificultad de los nuevos funcionarios del estanco fue recibir el tabaco que estaba en poder de los comerciantes particulares. En ese caso, la Real Hacienda tuvo que indemnizarles y pagarles el lucro cesante al procederse con la "estatización". Este trabajo, en realidad, no presentaba mayores contratiempos, en vista de que los principales comerciantes del tabaco actuaban casi bajo su libre albedrío, sin haber formado un gremio articulado o relativamente influyente, a pesar de que el estanco ya estaba voceado desde años antes; además, eran deudores de alcabala, lo que los colocaba en una situación aún más comprometida. En el cuadro aparecen los nombres de los principales empresarios de la venta del tabaco y sus deudas con el tesoro real.

Cuadro 9

Razón de los sujetos que deben alcabalas procedidas del efecto de tabacos, 1752

\begin{tabular}{ll}
\hline Nombres & Deuda por alcabala \\
\hline Joseph de Barrueta & $2,156.61 / 2$ \\
\hline Joaquín de Sotolonga & $2,402.11 / 2$ \\
\hline Domingo Saldivar & 225 \\
\hline Isidro Duradoña & 577.4 \\
\hline Francisco Ercilbenga & 375 \\
\hline Vicente Lee Flores & $1,287.6$ \\
\hline Francisco Montestruque & $2,262.6$ \\
\hline Lorenzo de Olasquaga & 367.4 \\
\hline Adrían Corsi & 463.4 \\
\hline Manuel Enrique & $1882.21 / 2$ \\
\hline Total & $12,000.21 / 2$ \\
\hline
\end{tabular}

Fuente: MORALES (2012: 45).

El siguiente tema crítico fue buscar, en Lima, un local adecuado para almacenar los tabacos en polvo y rama. El clima de la Ciudad de los Reyes, por sus altísimos índices de humedad atmosférica (por encima del 90\%), era 
poco apropiado para su conservación. Se decidió arrendar un inmueble particular en la calle Santa Teresa (también llamada del Padre Gerónimo, actual quinta cuadra del jirón Puno), que fue acondicionado a la mayor velocidad posible. Pero la casona en cuestión era chica y poco eficiente: el tabaco era arrumado uno encima de otro, sin respetar el orden de calidad y los precios de la compra; también se mezclaban los tabacos en polvo con los de hoja. Por otro lado, no había la adecuada ventilación, tampoco una tarima de madera que actuara como aislante del piso. En realidad, la mercadería era depositaba directamente en el suelo, de tierra apisonada, y pegado a las paredes, por lo que el polvo y la humedad de Lima actuaron de manera implacable. Todo un desastre, producto de la improvisación.

En esas condiciones, el tabaco se descomponía constantemente, acentuando las pérdidas. Además, el alquiler del inmueble era caro, y pertenecía a varios propietarios. A esto se añadía el sueldo de los operarios, que era otro gasto oneroso. Algunos recomendaron construir una casa $\circ$ un depósito apropiado. No se hizo, y se recurrió a otra solución para salvar la situación: se adquirió un solar contiguo por 3.500 pesos. Queda claro que todo se implementó dejando de lado mínimos criterios técnicos. Sin tomar las precauciones necesarias, el deterioro del tabaco era inminente, especialmente el de rama. Según los documentos de la época, las pérdidas que se registraron en ambos tipos de tabaco llegaron a alcanzar un valor similar al que hubiese costado fabricar una casa o depósito apropiados para el estanco y cumplir todos los procedimientos necesarios para su conservación.

Cabe añadir, por último, que, a partir de 1760, las autoridades del Virreinato peruano buscaron mejorar la cantidad y calidad del tabaco local para no depender de la importación de México, Cuba o Guayaquil, operación que se había tornado complicada porque en aquellos lugares también se había instaurado el monopolio estatal. Lo cierto es que, a pesar de estos aprestos, ni productividad ni la calidad mejoraron, por serios problemas de mano de obra, un mal sistema de selección y clasificación de la hoja del tabaco y, quizá lo más importante, un sistema general de funcionamiento del estanco que desalentaba la innovación. ${ }^{10}$

10 El estudio de Magdalena Chocano nos revela las razones de esta problemática: "La cuestión de la baja productividad se explica, en parte, por los hábitos de cultivo: se sembraban otras plantas entre las matas del tabaco y no se controlaban los tiempos de deshierbe, aporque y descogolle, procesos que si se hubieran realizado de modo ordenado habrían permitido que el tabaco alcanzara una mejor calidad. Asimismo, los cosecheros no recibían dinero en efectivo por la venta de mazos, sino que se les pagaba en ropa de la tierra, tasada a un precio muy 


\section{UN CASO DE EXCEPCIÓN: EL CORREGIDOR DE TRUJILLO, MIGUEL FEIJOO DE SOSA}

Uno de los funcionarios más valiosos con los que contó la administración virreinal para poner en práctica el estanco del tabaco fue Miguel Feijoo de Sosa, corregidor de Trujillo y autor de la Relación Descriptiva de la Ciudad y Provincia de Trujillo del Perú, escrita entre 1759 y 1760, y editada en Madrid en 1763. Sabedor de las calidades profesionales de Feijoo, atípico en comparación a los, por lo general, abusivos corregidores del siglo XVIII, formado en contabilidad, el nuevo Virrey, Manuel de Amat, le encomendó, con la confianza que le tenía, realizar un exhaustivo informe sobre la reorganización del estanco del tabaco en su estratégica jurisdicción, donde se cultivaba prácticamente el $100 \%$ de la hoja del tabaco. Como buen contador, Feijoo realizó un detallado trabajo, en el que también lanzó algunas recomendaciones.

Revisando libros y papeles, a fin de penetrar en la lógica del movimiento económico del estanco, a Feijoo le bastaron un par de semanas para darse cuenta del caos en la contabilidad del negocio del tabaco. Era 1763, y sólo se había llevado libros hasta 1754, cuando el estaco databa de 1752; un total desbarajuste. Nadie había rendido cuentas por más de diez años. Feijoo no sólo tuvo que enmendar la tarea de llenar ese enorme vacío contable, sino que redactó unas "Notas y Advertencias que dimanan de esta Cuenta General conducentes a su esclarecimiento y al perfecto arreglamiento del Real Estanco", fechadas el 30 de junio de 1766 (LOHMANN, 1984).

Entre sus recomendaciones, Feijoo subraya la necesidad de adecuar el cultivo con el consumo, a fin de mantener estable el precio del tabaco y evitar el excedente para atajar el contrabando. A continuación, pide verificar el costo de los fletes y alerta sobre los fraudes que se cometían (por ejemplo, señala, que el contenido de los zurrones que se recibían de Chachapoyas se alteraba con palos de balsa y de maguey, sin saberse si esta operación dolosa se cometía en el punto de origen, durante el transporte o ya en Trujillo donde se despachaba la mercadería).

superior al del mercado, con lo cual se estimulaba el contrabando y, a la vez, se desalentaba la innovación y la mejora de las técnicas de cultivo, lo que repercutían negativamente en el logro de una mayor productividad. En cuanto a las cifras de producción, es muy complicado obtenerlas. Además del circuito del contrabando que absorbía un porcentaje no definido de la producción, hasta la actualidad no se han encontrado datos directamente tomado de provincia" (CHOCANO, 2010: 71-72). 
Asimismo, insiste en la creación de un estanco en Tucumán, para evitar el contrabando de tabaco procedente de Sevilla, que era reenviado a Chile y Potosí. Al igual que en otras regiones de la América hispana y de la misma Península, Feijoo sugiere que las órdenes religiosas no trafiquen con tabaco pues, bajo el amparo de su fuero y sus privilegios fiscales, distorsionaban peligrosamente el mercado (da como ejemplo que en una celda del convento de los dominicos en Lima se había encontrado un molino para fabricar rapé). Finalmente, y ya ampliando sus horizontes como simple funcionario, Feijoo se proyecta a lo político: la necesidad de incorporar a la jurisdicción del Virreinato de Lima las provincias de Guayaquil y Jaén de Bracamoros (desde 1735 en el Virreinato de Nueva Granada) para controlar el tabaco procedente de México y Cuba (que desde Guayaquil entraba clandestinamente al Perú) y vigilar bien los cultivos del tabaco "bracamoros" (Jaén estaba muy distante, geográficamente, de lo que podían hacer las autoridades de Quito o Bogotá; desde Trujillo esa labor podía acometerse con mayor eficiencia). Según Lohmann (1984), el estupendo informe de Feijoo no sólo fue invalorable para la administración del virrey Amat, sino también a la de otros virreyes, como de Gil de Taboada y Lemos quien, cuando en 1790 quiso hacer otra reestructuración del monopolio del tabaco, recurrió al consejo del ex corregidor de Trujillo. ${ }^{11}$

\section{LOS PRIMEROS RESULTADOS}

Todos los trabajos historiográficos, al menos en esta etapa inicial de implantación del estanco del tabaco (1752-1762), coinciden en que esta medida, estatista y mercantilista, dio resultados positivos en sus objetivos fundamentales: consiguió aumentar los volúmenes de venta de tabaco y ampliar el mercado de consumo. Asimismo, tuvo saldos positivos para la burocracia, pues hizo crecer el empleo con una política salarial que premiaba la remuneración en función de las habilidades de administradores y estanqueros al recibir premios y porcentajes por las ventas efectuadas. De esta manera, se dio un estímulo eficaz para la venta al público consumidor (CÉSPEDES DEL CASTILLO, 1954 y 1995; KLEIN, 1998; FLORES, 2010; y MORALES, 2012 y 2015$).$

11 Los informes de Feijoo se ubican dentro del conjunto de análisis de la problemática general del Virreinato, haciendo diagnósticos detallados, y orientados a introducir reformas políticas y a renovar el sistema general de toda la administración pública. Feijoo ofrece soluciones, propone impulsar la prosperidad de la región de Trujillo mediante el aprovechamiento racional de los recursos y fuentes de riqueza que posee la costa norte de Perú. 
En cuanto a la recaudación fiscal, los resultados fueron relativamente modestos, en comparación con el consolidado de la etapa anterior al estanco, como lo demuestra el cuadro 2 (KLEIN, 1998), que consigna los ingresos de todos los estancos, pero básicamente al tabaco. ${ }^{12}$

Cuadro 2

Ingresos de tabaco en rama a la ciudad de Lima (1725-1743)

\begin{tabular}{lrrr}
\hline Regiones & \multicolumn{1}{l}{$\begin{array}{l}\text { Número } \\
\text { total de } \\
\text { fardos } \\
\text { ingresados }\end{array}$} & Porcentaje & $\begin{array}{l}\text { Promedio } \\
\text { anual de } \\
\text { fardos } \\
\text { ingresados }\end{array}$ \\
\hline Saña & 19,255 & $45 \%$ & $1,040.8$ \\
\hline Moyobamba & 362 & $1 \%$ & 19.5 \\
\hline Bracamoros & 17,525 & $40 \%$ & 947.2 \\
\hline Luya y Chillaos & 700 & $2 \%$ & 37.8 \\
\hline Guayaquil & 3,831 & $9 \%$ & 207.0 \\
\hline La Habana & 1,512 & $3 \%$ & 81.7 \\
\hline Total & 43,185 & $100 \%$ & $2,334.0$ \\
\hline
\end{tabular}

Fuente: MORALES (2013: 153)

Sin embargo, a largo plazo, si el estanco del tabaco no siguió creciendo eficazmente como empresa estatal, fue por un conjunto de factores, algunos recurrentes, que terminaron imponiéndose frente al ímpetu inicial por parte del gobierno virreinal y la obligada colaboración de funcionarios, vendedores y consumidores. En un plazo mediato, se reactivaron el contrabando y el comercio ilícito, por ejemplo. La Corona, por su lado, siempre tenía que atender gastos urgentes e imprevistos, dadas las características del convulsionado siglo XVIII. Los vicios de la administración pública también pusieron su cuota de desorden, como las malas prácticas (presiones) de los cuestionados corregidores frente a funcionarios que querían cumplir con su deber o la mala práctica (o voluntad) de algunos trabajadores del estanco, no calificados para esta tarea, y los altos salarios que cobraban los máximos responsables del monopolio.

12 De forma subsidiaria, el cuadro también recoge la recaudación de otros productos estancados, como naipes, papel sellado, breas y pólvora. 
Mientras todo esto ocurría, el peculiar clima de Lima hacía lo suyo. Pero dentro de este habitual desorden, una medida inteligente fue la estatización de la Fábrica de Cigarros, lo que le permitió al estado virreinal practicar una economía mixta, al combinar el estatismo con el liberalismo comercial. Esa línea del negocio dio réditos positivos, tanto para la renta, la caja fiscal y el personal contratado.

Ahora, el funcionamiento de la Fábrica de Cigarros abre una interesante discusión respecto a la relativa modernización de aquel sector fabril en el marco de la economía urbana limeña de finales del Virreinato pues, en primer lugar, tuvo que instalarse maquinaria para transformar la hoja de tabaco en los diversos artículos que demandaba el mercado de consumidores, así como incrementar el volumen de producción. Asimismo, ayudó a formar una mano de obra más calificada, un artesano más productivo, activo y racional, aunque, pensamos, es muy aventurado afirmar que existió un intento, a través de reglamentaciones y prohibiciones, de "proletarizar" aquella mano de obra orientada a la manufactura de cigarros y cigarrillos. No se debe soslayar, por último, los esfuerzos en profesionalizar la gestión del estando del tabaco, hacer más eficiente la labor de sus dependientes y funcionarios.

Todo estuvo aparentemente bien compaginado hasta que llegó, en 1778, la ley de libre comercio, que obligó a poner fin al programa de intervención estatal sobre el negocio del tabaco. Uno de sus efectos fue el cierre de las fábricas de cigarros estatales, provocando, un conflicto entre la fuerza laboral y el Estado. A su vez, los cigarreros ahondaron sus diferencias cuando el Estado les incrementó el precio de la venta de sus artículos, negándose a comprar una mayor cantidad de tabaco, lo que perjudicó la renta del negocio. En síntesis, fue negativo el abandono por parte del Estado del sector fabril, pues se truncó su tecnificación (o su innovación) y, en un ejercicio contrafactual, se perdió la oportunidad de consolidar una "industria" local bajo el patrocinio estatal. ${ }^{13}$

De todos modos, la empresa por estancar el tabaco, en su primera etapa, a nivel fiscal, dio resultados modestos, teniendo en cuenta el desgaste administrativo y político que tomó su aplicación. Si el objetivo de la Corona era maximizar la hacienda pública, los ingresos debieron venir de otros

13 En esta dirección, es útil la revisión de HERNÁNDEZ SOCORRO, María de los Reyes y LUXÁN, Santiago de (2015), "Dos proyectos de construcción de una fábrica de trabajo en Lima durante el virreinato de Teodoro de Croix (1785 y 1788)", en LUXÁN, Santiago de, FIGUEIROA-REGO, João y SANZ ROZALÉN, Vicent (eds.), Tabaco e escravos nos impérios ibéricos, Universidad Nova de Lisboa, Lisboa, pp. 121-138. 
impuestos directos, más lucrativos. Allí sí hubo un verdadero cambio, que también refleja el crecimiento económico que experimentó el Virreinato peruano, a pesar de todos los infortunios que tuvo que atravesar en el siglo $\mathrm{XVIII}$, como la pérdida de territorios, los desastres naturales o el descontento social.

\section{Biblografía}

CARCELÉN, Carlos, MORÁN, Daniel y AMADOR, Laura (2020), "El terremoto de 1746 y su impacto en la salud en la ciudad de Lima", Revista Peruana de Medicina Experimental y Salud Pública, vol. 37/I, pp. 164-168. CÉSPEDES DEL CASTILLO, Guillermo (1954), "La renta del tabaco en el Perú, Revista Histórica, t. XXI, pp. 138-163.

CÉSPEDES DEL CASTILLO, Guillermo (1992), "Reorganización de la hacienda virreinal peruana en el siglo XVIII", Anuario de Historia del Derecho Español, vol. 23, pp. 329-370.

CHOCANO, Magdalena (2010), "Población, producción agraria y mercado interno, 1700-1824", en CONTRERAS, Carlos (ed.), Compendio de historia económica del Perú. Economía del periodo colonial tardío, vol. 3, Banco Central de Reserva del Perú / Instituto de Estudios Peruanos, Lima, pp. 19-101.

ESCOBAR GAMBOA, Mauro (1973), El tabaco en el Perú colonial (17521796), Tesis de Bachiller, UNMSM, Lima.

FLORES, Ramiro (2010), "Fiscalidad y gastos de gobierno en el Perú borbónico", en CONTRERAS (ed.), Compendio de historia económica del Perú, pp. 295-380.

HERNÁNDEZ SOCORRO, María de los Reyes y LUXÁN, Santigo de, "Dos proyectos de construcción de una fábrica de trabajo en Lima durante el virreinato de Teodoro de Croix (1785 y 1788)", en LUXÁN, Santiago de, FIGUEIROA-REGO, João y SANZ ROZALÉN, Vicent (eds.), Tabaco e escravos nos impérios ibéricos, Universidad Nova de Lisboa, Lisboa, pp. 121-138.

KLEIN, Herbert (1998), The American Finances of the Spanish Empire. Royal Income and Expenditures in Colonial Mexico, Peru, and Bolivia (16801809), University of New Mexico Press, Albuquerque.

LAZO GARCÍA, Carlos (2006), Historia de la economía colonial, vol. 1, UNMSM, Lima.

LÉVANO MEDINA, Diego (2014), "Artesanos del humo. El gremio de cigarreros y limpioneros de Lima en el siglo XVIII", Revista del Archivo General de la Nación, n²9, pp. 103-140. 
LLANO ZAPATA, Eusebio (2005), Memorias histórico, físicas, crítico apologéticas de la América Meridional, IFEA / PUCP / UNMSM, Lima.

LOHMANN, Guillermo (1984), "Miguel Feijoo de Sosa: el hombre y su obra", en FEIJOO DE SOSA, Relación Descriptiva de la ciudad y provincia de Trujillo del Perú, edición facsimilar, 2 vols., Banco Industrial del Perú, Lima, vol. 1, pp. 13-82.

MORALES, Carlos (2012), "Mercantilismo y crecimiento económico en el virreinato del Perú. El Estanco del Tabaco 1750-1800", Investigaciones Sociales, vol. 15/28, pp. 35-47.

MORALES, Carlos (2013), "Comercio y mercado del tabaco en la gobernación de Jaén de Bracamoros en la primera mitad del siglo XVIII", Investigaciones Sociales, vol. 17/31, pp.147-153.

MORALES, Carlos (2015), Mercantilismo y crecimiento económico en el Virreinato del Perú. La organización del estanco del tabaco. Lima (17501800), Tesis de Magíster, UNMSM, Lima.

OLIVERA ORÉ, Julio (1979), La renta del tabaco en el Perú en el siglo XVIII, Tesis de Bachiller en Historia, UNMSM, Lima.

PÉREZ-MALLAÍNA, Pablo (2005), "Las catástrofes naturales como instrumento de observación social: el caso del terremoto de Lima en 1746", Anuario de Estudios Americanos, vol. 62/2, pp. 47-76.

QUIROZ, Francisco (2010), "Industria urbana y rural en el periodo colonial tardío", en CONTRERAS, Carlos (ed.), Compendio de historia económica del Perú, pp. 169-222.

UNANUE, Hipólito (1964-1966 [1792]), “Disertación sobre la naturaleza y efectos del tabaco, adornada con una breve idea del origen y progresos del Real Estanco de Lima", Mercurio Peruano, vol. IV, Biblioteca Nacional del Perú, Lima, pp. 35-51.

VIZCARRA, Catalina y SICOTTE, Richard (2002), "El control del contrabando en el Perú colonial: el caso del monopolio del tabaco, 1752-1813", en Estado y mercado en la historia del Perú, PUCP, Lima, pp. 184-211. 